Revista Española de Antropología Americana

ISSN: 0556-6533

https://dx.doi.org/10.5209/reaa.79902

\title{
Alfredo López Austin (1936-2021-siempre)
}

En la era de las comunicaciones inmediatas, la noticia nos llegó rápidamente, con la consiguiente dosis de tristeza. En esta misma era, glosar los méritos académicos del Dr. Alfredo López Austin es completamente innecesario. Cualquiera, aún no avezado en los motores de búsqueda de internet, puede encontrar numerosas informaciones, con posibilidad de acceder a su enorme bibliografía y poder leer en el momento muchos de sus trabajos. E incluso verle y escucharle en video. Además, en el homenaje tan merecido que se le brindó en forma de libros (son 3 volúmenes) en 2017, por el Instituto Nacional de Antropología de México y la Universidad Nacional Autónoma de México, coordinado por Eduardo Matos Moctezuma y Ángela Ochoa, hay un volumen completo dedicado a su vida y obra (ALA_Vida-y-obra. pdf mesoweb.com) en el que se pueden contemplar los múltiples ámbitos en los que se desarrolló su quehacer. Y como gran acierto, comienza con una "Semblanza de mí mismo" obra del mismo homenajeado, en la cual podemos contemplar algunos de sus rasgos característicos, como su gran sentido del humor.

Mi contribución al homenaje y al recuerdo (imperecedero) va a ir en la línea de esa semblanza: mis Martha y Alfredo, siempre juntos.

Comienza con un recuerdo a sus maestros, a sus primeros maestros, los que pusieron las bases de la inquietud, la seriedad en el trabajo y la preocupación por los demás. Gran rasgo de humanidad que deberíamos imitar. Como la semblanza es muy breve, apenas menciona algunos puntos de su trayectoria que a sus ojos fueron importantes, en un "elogio a la vanidad" que incluye otra instantánea de su proceder vital y académico: "Todo es útil en esta vida, hasta la vanidad". Con esa perspectiva, podemos comprender mejor la variedad y riqueza de su obra, más allá de los breves fragmentos que él comenta. Desde La constitución real de México Tenochtitlan (1961), imprescindible para los que estudiamos la política y la economía prehispánica, a Tarascos y mexicas (1981), para este autor el mejor panorama del México Prehispánico en su momento, afectado por los avances realizados en estos últimos 40 años, pero todavía muy útil de leer. Eso sí, superado por El pasado indígena (1996) en coautoría con Leonardo López Luján, en una primera entrega de una fecunda colaboración que nos llena de envidia, sana, por supuesto. De las mismas plumas, entre otras obras: Mito y realidad de Zuyúa (1999) y Monte Sagrado-Templo Mayor (2009). Entre ellos, el análisis del mito y la persona de Quetzalcoatl y su monumental tesis sobre Cuerpo Humano e ideología (1980), y las numerosas entregas sobre aspectos distintos de los textos de fray Bernardino de Sahagún. No hay que olvidar su constante participación en obras de divulgación y su interés por que el conocimiento llegue a la mayor cantidad de gente posible, y de una forma accesible. Esa lucha fue una de las constantes de su trayectoria y está ligada al deseo de ayudar a mejorar el mundo. 
A ello contribuía su interés por todo, por lo que supone conocimiento y por el trato con los demás.

Mi mundo lo mejoró sin duda con su trato y su ejemplo. Desde la primera vez, en el entonces Distrito Federal, cuando un consagrado investigador recibió y atendió a un jovencito principiante, haciéndole sentir más importante de lo que era, ya que entonces desconocía que ese era el comportamiento habitual del maestro. Más adelante, tuve la fortuna de compartir "despacho" en Madrid con él y algunos compañeros más, pues en el curso de una estancia de Alfredo en el entonces Departamento de Antropología y Etnología de América de la Universidad Complutense de Madrid, recibió una mesa en la biblioteca del Departamento, junto a las que ocupábamos los becarios pre- y postdoctorales, así que nos veíamos a diario y abusábamos de su bondad, preguntándole infinidad de cosas y recibiendo asesorías gratis. No dudaba en ayudar. Un ejemplo, Ángel Barral estaba entonces traduciendo del francés al castellano un libro de Michel Graulich sobre religión azteca, y Alfredo fue un generoso asesor en cuantas preguntas surgieron. Pocos años después, en una nueva estancia, siendo yo ya profesor y teniendo un seminario sobre Mesoamérica, con algunos alumnos destacados (que luego en su mayoría han devenido importantes investigadores), le pedí que acudiera a algunas de nuestras sesiones para hablarnos de lo que le pareciera oportuno. Accedió, pero me dijo "lo haces para que pongan cara a las fichas bibliográficas" y yo le contesté "no, es para presumir de amistades". Vino y disfrutamos de su presencia y de su habla. Ya me he referido antes a algunos de sus escritos, siempre claros, pese a la densidad de lo expuesto. Hay mucha miga en sus propuestas, pero en este momento quiero destacar la faceta de orador y de conversador de Alfredo. Hay mucho que aprender ahí y por suerte hoy día podemos reproducir conferencias y entrevistas con él, cosa que no hace tanto era muy difícil. En una de esas conversaciones me dijo una vez algo que me impactó: "José Luis, voy a estar un tiempo sin publicar nada nuevo, pues he comenzado una investigación sobre un nuevo tema, y llevará algún tiempo tener algo que decir". Verdad de Perogrullo, confesión que debemos compartir, ejemplo con humildad y realismo.

No voy a entrar en cosas más íntimas, que las hubo, pero no me resisto a comentar una anécdota que muestra su rapidez de reflejos y su sentido del humor. Una vez, ya casado yo, que Martha y Alfredo vinieron a comer a casa, se presentaron con una tarta y nosotros les regañamos con cariño, pues no era necesario que hubieran llevado nada. Rápido como una centella, Alfredo respondió: "lo que no sabes es que como soy muy goloso, soy hombre de dos postres, y por si acaso..."

Entre las muchas cosas académicas que nos deja, está su habilidad para tocar los temas importantes y por haber acuñado esa expresión del "núcleo duro":

La aplicación de la tesis braudeliana de los ritmos de la historia permite formular la distinción entre los diferentes ritmos de transformación en la continuidad histórica de la tradición mesoamericana y explicar en ella la díada unidad/diversidad. Esta díada se origina en el juego entre los procesos lentísimos de transformación y otros menos lentos, hasta llegar a los elementos muy lábiles al paso del tiempo. El conjunto de los elementos de la cosmovisión caracterizados por su transformación más lenta se ha denominado núcleo duro. (Alfredo López Austin, "Semblanza de mí mismo" 2018, p. 17). 
Creemos que la expresión es muy acertada, pero que se puede aplicar a otros ámbitos y hasta relacionar con el inicial concepto de "Mesoamérica" propuesto por Paul Kirchhoff: es importante ver lo que caracteriza el área cultural y eso tiende a ser lo permanente. Claro que el núcleo duro se puede ir ampliando con el tiempo, y comenzaríamos a hablar del concepto de tradición y sus tiempos. Tengo pendiente esta conversación con Alfredo, pero de momento me conformo con dialogar con sus textos, eso sí, con su voz. Entre mis manías está el personificar a los protagonistas de los libros que leo, bien con conocidos, bien con actores y actrices, así que cuando leo a algún autor que conozco, escucho su voz, y si pregunto algo al texto, me contesta. Ahora con más razón, escucharé lo que me sigue teniendo que decir y enseñar Alfredo López Austin, un imprescindible para todo mesoamericanista y para toda persona que lo haya conocido en su faceta humana y luchadora.

Su propia opinión sobre su vida termina la mencionada semblanza como resumen y es bueno repetirla:

Hago el balance frente a mi árbol: muchos números rojos; muchos negros; los negros superan a los rojos. ¡Estoy contento! Es que el árbol se dio en buen terreno: un bosque tupido, de oxígeno denso. Lo cuidé mejor que peor, y mucho mejor que peor lo rodearon los árboles vecinos. Me fue bien, y el deseo que me queda es que igual les vaya a los siguientes que siguen.

Un cierto orgullo en la conciencia de haberlo hecho bien, con ayuda de los demás, y el deseo de que las cosas continúen así en las generaciones siguientes delatan el fondo de la personalidad de Alfredo López Austin al que podemos aplicar unas palabras de Antonio Machado en su Retrato: "y, más que un hombre que sabe su doctrina, / soy, en el buen sentido de la palabra, bueno".

Un hombre sabio y bueno, que ha repartido sabiduría y cariño por todo el mundo se ha apartado de nosotros, pero no nos ha dejado del todo. En nuestras investigaciones, en nuestros recuerdos, siempre estará el magisterio vital de Alfredo.

José Luis de Rojas

Universidad Complutense de Madrid 
